\title{
Poder económico y la industria energética en Monterrey. Una visión desde el derecho humano al agua
}

\author{
Economic power and energy industry in Monterrey. \\ $A$ view from the human right to water
}

\begin{abstract}
Magda Yadira Robles
Licenciada en Derecho por el Instituto Tecnológico y de Estudios Superiores de Monterrey - (ITESM); especialista en Docencia a Nivel Superior por el Programa de Postgrado de la División de Ciencias de la Educación y Humanidades de la Universidad de Monterrey; magíster en Ciencias de la Educación por la Universidad de Monterrey; especialista en Argumentación Juridica por la Universidad de Alicante, España. Doctora en Derecho - Programa Derechos Fundamentales por la Universidad Carlos III de Madrid, España; profesora investigadora del Departamento Académico de Derecho, División de Derecho y Ciencias Sociales de la Universidad de Monterrey, México. Correo electrónico: Magda.robles@udem.edu.mx
\end{abstract}

\section{Oscar Flores Torres}

Licenciado en Historia por la Universidad Autónoma de Nuevo León (UANL), Monterrey, N.L., México; licenciado en Antropología Social por la Universidad Autónoma de Nuevo León (UANL), Monterrey, N.L., México; magíster en Historia por El Colegio de Michoacán, A. C., Zamora, Michoacán, México; doctorado en Ciencias de la Información, Programa Historia Contemporánea por la Universidad Complutense de Madrid, España; profesor investigador de El Colegio de Tamaulipas, México.

Correo electrónico: oflores60@gmail.com

\begin{abstract}
Resumen
El texto aborda la puesta en marcha de proyectos de infraestructura y desarrollo desde la reforma energética de 2013 en México. A partir del caso "Monterrey VI" se analiza en perspectiva histórica el proyecto hídrico que proveerá de agua a la competitiva ciudad industrial del norte de México con la confluencia del sector público y privado para solventar sequías de la urbe de cerca de cinco millones de habitantes y agua dulce para explorar la novedad minera global: la extracción de gas shale. En este contexto pasado y presente, los derechos humanos nos presentan un futuro inmediato que los une: la protección a la persona humana y su relación con el entorno. La investigación pretende mostrar los parámetros sobre los cuales se determinará la viabilidad de los proyectos y el impacto que traerán para el respeto y protección de los derechos humanos.
\end{abstract}

Palabras clave: Energéticos, derechos humanos, agua, medioambiente, empresas.

\begin{abstract}
The text deals with the implementation of infrastructure projects and development from 2013 energy reform in Mexico. From the case "Monterrey VI" the water project that will provide water to the competitive industrial city in northern Mexico with the confluence of public and private sector to address droughts in the city of nearly five million inhabitants is analyzed in historical perspective and / or sweet to explore new global mining water: the extraction of shale gas. In the past and present context, human rights show us the immediate future that unites them: the protection of the human person and his relationship with the environment. The research aims to show the parameters on which the viability of the projects and the impact that will bring for the respect and protection of human rights will be determined.
\end{abstract}

Keywords: Energy, human rights, water, environment, industry.

Recibido: 30 de julio de 2015; Aprobado: 2 de octubre de 2015 


\section{Résumé}

Le texte traite de la mise en œuvre des projets d'infrastructure et de développement depuis 2013 la réforme de l'énergie au Mexique. De le cas du projet de l'eau qui fournira de l'eau à la ville industrielle compétitive dans le nord du Mexique au confluent du secteur public et privé pour faire face sécheresses dans la ville de près de cinq millions d'habitants «Monterrey VI» est analysée dans une perspective historique et de l'eau fraîche pour explorer la nouveauté minière mondiale: l'extraction du gaz de schiste. Dans ce contexte, passé et présent, les droits de l'homme nous montrent l'avenir immédiat qui les unit: la protection de la personne humaine et sa relation avec l'environnement. La recherche vise à montrer les paramètres sur lesquels la viabilité des projets et l'impact qu'ils apportent au respect et à la protection des droits de l'homme seront déterminés.

Mots-clés: l'énergie, les droits de l'homme, l'eau, l'environnement, les entreprises. 


\section{Poder económico y la industria energética en Monterrey. Una visión desde el derecho humano al agua*}

Magda Yadira Robles

Oscar Flores Torres

\section{MONTERREY, CIUDAD INDUSTRIAL}

Tal como sucedió en el ámbito nacional, el creciente desarrollo económico del área metropolitana de Monterrey (AMM), México, del período de 1930 (especialmente a partir de 1940) a 1994, fue acompañado por un aumento paralelo en la refinación y consumo de hidrocarburos. Está fuera de toda sospecha, que sin el incremento de su producción no hubiera sido posible el desarrollo económico, dado la fuerte dependencia de la industria, los transportes y los energéticos mismos de esta materia auxiliar (Flores, 2009).

Amén de lo que representan los hidrocarburos como un elemento decisivo en la rápida expansión de la industria automotriz, el desarrollo de la industria metalúrgica y siderúrgica del AMM se apoyó fundamentalmente en la disponibilidad abundante y relativa del bajo costo de los hidrocarburos.

Esto fue así por un fenómeno particular en el caso de Monterrey. Aunque comúnmente se considera que con el inicio en 1931 de la construcción de la refinería de Azcapotzalco en la ciudad de México, principia la primera red troncal de hidrocarburos, en realidad esto no fue así. Este proceso ya existía en Monterrey. A

* El artículo es resultado del proyecto de investigación: La reforma energética y sus impacto en el Noreste de México, proyecto interinstitucional inscrito en el Centro de Estudios Históricos de El Colegio de Tamaulipas, y participan investigadoras del Departamento de Derecho de la Universidad de Monterrey y del Centro de Investigación de Tecnología Jurídica y Criminológica (CITEJYC) de la Facultad de Derecho y Criminología de la Universidad Autónoma de Nuevo León, México. 
medida que la ciudad norteña continuaba su acelerado proceso de industrialización y crecimiento de la población, los hidrocarburos tuvieron su arribo a través de este sistema en 1930.

En efecto, en esa época en el estado de Nuevo León no se realizaban actividades de extracción de petróleo ni de gas natural (PEMEX, 1988) $)^{1}$, pero la obtención de los hidrocarburos necesarios para la industria se obtuvo a través de importantes inversiones en infraestructura, por parte del poderoso grupo industrial con asiento en Monterrey. Así, construyeron el primer ducto más importante en 1928, gasoducto que unió San Pedro de Roma, Tamaulipas y la ciudad de Monterrey, el cual entró en operación en 1930. La longitud de este gasoducto pionero fue de 155.2 kilómetros y transportó 850 mil metros cúbicos diarios de gas, a la capital del estado de Nuevo León. Esta línea que consistía en una tubería de acero de 311 milímetros de diámetro, se conectaba con el gasoducto que cruza el río Bravo desde Roma, Texas y el cual provenía del campo de gas de Jennings, condado de Zapata, Texas, en Estados Unidos de América (Flores, 2010).

Así, tendencias similares pueden observarse en otras ramas industriales predominantes en el AMM (cemento, minero-metalúrgica, papelera, sustancias químicas, productos derivados del petróleo, productos de hule y plástico, entre otros) en las que la oferta suficiente de este energético ha sido crucial para su desarrollo.

El desarrollo económico de la ciudad de Monterrey se debió en gran medida al apoyo del sector público en cuanto a la infraestructura y las condiciones necesarias para que se diera tal emprendimiento. Sin embargo, debe destacarse en este análisis el papel preponderante que la elite empresarial jugó en los años cruciales del auge industrial. Hoy, a más de 50 años de estos inicios, el empresariado regiomontano se encuentra a la cabeza en los proyectos de desarrollo e infraestructura que la reforma energética llevada a cabo en México, en 2013 trajo consigo.

Este papel preponderante en el desarrollo económico que vimos en el pasado se encuentra hoy presente en las negociaciones para las explotaciones y exploraciones de hidrocarburos en zonas terrestres. El impacto en los derechos humanos que estas actividades tendrán en las comunidades en las que se llevará a cabo, es el propósito principal de estas líneas.

1 Al iniciar el siglo XX se detectaron campos de gas en la línea fronteriza del nordeste mexicano, especialmente al norte del estado de Nuevo León y Tamaulipas. Estos campos fueron explotados comercialmente por compañías petroleras privadas extranjeras (en especial estadounidenses) en la década de los veinte, con algunas dificultades técnicas y de costos. Casi toda esta producción era transportada a la capital del estado de Nuevo León, para dotar de energéticos a la industria de Monterrey. Sería hasta 1958, cuando Petróleos Mexicanos puso en servicio el segundo gasoducto para conducir el gas producido en los yacimientos del norte, cerca de Reynosa, hasta Monterrey, Saltillo y Torreón. Constaba de dos tramos de tubería, uno de 22 pulgadas con 225 kilómetros de extensión, entre Reynosa y Monterrey, y otro de 16 pulgadas con 310 kilómetros de extensión, de Monterrey a Torreón, con un ramal de 30 kilómetros para dotar de gas a la capital de Coahuila. 
Para realizar el análisis que se propone usaremos el estudio de un caso: Proyecto Monterrey VI, obra hídrica de dimensiones financieras sin precedentes en nuestro Estado que abastecerá de agua la zona metropolitana de Monterrey para las próximas décadas. Interesa por tanto, analizar los criterios judiciales que -desde la óptica de la Corte Interamericana de Derechos Humanos y de los tribunales mexicanos- se aplicarán en la protección de los derechos humanos, especialmente, la discrepancia por el vital líquido.

\section{REFORMA ENERGÉTICA}

Esta reforma se aprobó en México en diciembre de 2013 en los artículos 25, 27 y 28 constitucionales. Según la iniciativa, el objetivo central era recobrar para México la seguridad energética. El argumento fue contundente: la inercia del modelo anterior haría a México importador neto, dentro de tres años, de todas sus energías primarias.

Recobrar esa seguridad requería dos elementos esenciales: seguridad jurídica y competencia efectiva. Igualmente, poner punto final a los monopolios, en este caso públicos. Así como dar garantías a inversiones que suponen horizontes de tiempo de operación de 20 a 30 años.

Recientemente, en mayo de 2015, la Comisión Nacional de Hidrocarburos (CNH) publicó la tercera convocatoria de la Ronda Uno, como parte de la reforma energética que busca apuntalar la estancada producción de crudo y gas del país. En otras palabras, señala la intención: "Se convoca a personas morales nacionales o extranjeras y a empresas productivas del Estado a participar en la Licitación para la adjudicación de Contratos para la Extracción de Hidrocarburos en veintiséis Áreas Contractuales terrestres", dice el documento publicado en el Diario Oficial de la Federación. Cinco de estos campos están ubicados en el estado de Chiapas, ocho en Nuevo León, cinco en Tabasco, dos en Tamaulipas y seis en Veracruz (CNNExpansión, 2015).

En total, esta tercera convocatoria busca adjudicar 26 áreas terrestres. En todos los casos hay un contrato de licencia que obliga a las empresas a realizar un plan de desarrollo que señale la estimación de volúmenes in situ y reservas probadas, probables y posibles para cada yacimiento encontrado. Destaca que el contrato petrolero debe especificar cantidades en petróleo, condensados y gas natural (Rangel, 2015).

El impulso que el gobierno mexicano está dando al magno proyecto de privatización del sector energético, queda manifiesto al ver que la tercera fase de la Ronda Uno fue aprobada por la CNH. Instancia que ya otorgó dos licitaciones de contratos de exploración y explotación en aguas someras del Golfo de México. Los contratos para esta tercera fase son de licencia, mientras que los de las dos anteriores eran de producción compartida.

Sin embargo, este magno proyecto se enfrenta a uno de los grandes problemas que ha traído este boom de las redes energéticas en el noreste del país. En efecto, nos referimos a la falta de un líquido vital: el agua. Líquido que si bien es escaso en esta 
parte de la república ahora es de trascendental importancia, para un nuevo proyecto de extracción de otro energético asociado con el petróleo: el gas.

\section{EL GAS Y EL DERECHO HUMANO AL AGUA}

Para la perforación del subsuelo en busca de gas shale se planea utilizar por parte del gobierno del Estado de Nuevo León, la técnica de fracking, procedimiento que necesita inyectar grandes cantidades de agua no salada para fracturar las piedras que almacenan el hidrocarburo. Sin embargo, el director de infraestructura hidroagrícola del Organismo de Cuenca de Río Bravo, dio a conocer que el Consejo Nacional del Agua (Conagua) ha detenido las concesiones de pozos de agua para nuevas empresas. Esto se debe a que la cuenca de río Bravo actualmente (2014-2015) se encuentra sobreexplotada. Este hecho ha obligado a los grupos empresariales que planeen perforar -a fin de extraer el gas de lutitas (shale)-, busquen otras alternativas, además de las cuencas y ríos de la región. Uno de estos proyectos alternativos es el llamado proyecto de Monterrey VI.

Por otra parte, si bien el acceso al agua es ya un derecho humano en México, la iniciativa de la nueva Ley de Aguas en México contempla algunos puntos críticos. En efecto, la iniciativa ha enfrentado a grupos ambientalistas y al gobierno federal, porque según sus detractores esta ley contraviene los estándares mínimos en materia de agua dados por la Organización Mundial de la Salud y porque podría perjudicar en mayor medida a las comunidades indígenas o rurales.

Recordemos que en México -en el año de 2014-, al artículo 4 constitucional se le agregó el "derecho humano al agua", el cual establece que toda persona posee este derecho al acceso, disposición y saneamiento de agua para consumo personal y doméstico en forma suficiente, salubre, aceptable y asequible. Dos de las más severas críticas al proyecto han sido, primero, la posibilidad que la ley establece para que el gobierno otorgue concesiones hasta por cinco años y, segundo, la participación de las empresas privadas en el desarrollo de infraestructura hidráulica y la producción de energía eléctrica.

Este segundo punto, sin duda, es el más delicado. Porque afecta directamente a los consumidores en el pago por el abastecimiento del líquido para uso doméstico.

Interesa para nuestro tema el aspecto sobre los "trasvases" que plantea la iniciativa. Esto significa obras hidráulicas que buscan incrementar la disponibilidad de agua en una población, desviando la cuenca de un río vecino, como es el caso del Proyecto Monterrey VI que veremos más adelante. Sin duda, aunque si bien no se mencionan explícitamente en la ley es probable que este tipo de obras recurran al llamado fracking para el uso industrial del agua.

Al respecto, legisladores y sectores sociales de nuestra comunidad se han opuesto a esta iniciativa, argumentando que otorgaría a los consorcios que están operando y distribuyendo el agua una facilidad para no respetar los derechos territoriales de 
una comunidad, lesionando con ello, derechos fundamentales para las personas y poblaciones. La discusión para aprobar la ley se encuentra actualmente (2015) suspendida en el Congreso de la Unión. Sin embargo, por ahora, el proyecto Monterrey VI sigue adelante en esta entidad federativa.

\section{EL PROYECTO "MONTERREY VI"}

El proyecto nace de un estudio de la Comisión Nacional del Agua, la cual prevé que la región enfrentará un déficit severo de agua para los próximos años. Para este proyecto hídrico de enorme infraestructura se estima una inversión total de 13644 millones de pesos con recursos que provendrán del Fondo Nacional de Infraestructura, -el cual derivará del Presupuesto de Egresos de la Federación-, además se contempla la figura jurídica denominada Asociación Público Privada (APP) conforme a la Ley Federal en la materia.

El proyecto Monterrey VI, el cual fue presentado por el Gobierno de Nuevo León en marzo del 2014, tiene contemplado abastecer de agua al sector energético del noreste y en particular de Nuevo León. En efecto, la Secretaría de Desarrollo Económico del Estado de Nuevo León elaboró y presentó el documento titulado Reto Desarrollo Regional Energía 2014. Esta detalla la infraestructura del plan estratégico con la finalidad de desarrollar la zona de la Cuenca de Burgos en Nuevo León, mediante la extracción de gas shale. Esta tecnología requiere inyectar millones de litros de agua en el subsuelo.

El documento menciona expresamente a "Monterrey VI" como parte de la infraestructura para obtener el gas en el estado (SDE-NL, 2014). La presentación detalla la inversión de mil millones de dólares en la obra hidráulica con la que pretenden garantizar el abasto de agua para los próximos 50 años en Nuevo León, con 520 kilómetros de acueductos provenientes del río Pánuco. «Suficiente agua para las compañías que exploten el gas shale», señala el texto (Jiménez, 2014).

Organismos ambientalistas internacionales dieron a conocer que para la extracción de gas shale de un solo pozo, se requieren entre 9000 y 29000 metros cúbicos de agua. "La Alianza Mexicana contra Fracking", ha expresado que la extracción de gas shale se encuentra ligada con la contaminación del agua y la generación de sismos (De la Garza, 2015).

Igualmente, el Congreso del estado de Nuevo León, pidió iniciar una investigación para determinar si la extracción del gas shale tenía una vinculación a los numerosos sismos ocurridos recientemente en la entidad (Jiménez, 2014).

Luego de confirmarse que una parte del Proyecto Monterrey VI será para la extracción de gas shale mediante el método de fracking, especialistas advirtieron que el agua utilizada para este proceso queda contaminada por tóxicos, arriesgando además a la contaminación de mantos freáticos, cosechas y zonas completas. Una de estas voces fue dada a conocer por Green Peace, organización que advirtió, que el agua que se utiliza bajo este método queda contaminada. En otras palabras, el agua 
no puede ser tratada posteriormente y mucho menos puede servir para el consumo humano (Ochoa, 2014).

Por otra parte, el Proyecto Monterrey VI, puede llegar a tener otras aristas. De acuerdo con el Instituto Nacional de Antropología e Historia (INAH) en el estado de Nuevo León, este organismo tiene registrados más de mil 600 sitios arqueológicos, la mayoría ubicados en zonas no urbanas de la entidad (Lemus, 2014).

Más de un centenar de sitios con evidencia arqueológica estarían en riesgo de desaparecer o ser alterados ante la llegada de infraestructura destinada al desarrollo energético y de vivienda en los municipios de la zona norte y oriente de Nuevo León. La preocupación es manifiesta.

En el 2011 se elaboró otro mapa con mayor detalle (INAH, 2011). Este registro contabilizó cerca de 1400 sitios arqueológicos, distribuidos principalmente entre los siguientes municipios del estado de Nuevo León: Mina, García, Doctor González, Cadereyta, Los Ramones, Aramberri y Zaragoza.

Especialistas en la materia han comentado que la zona oriente y centro de Coahuila junto a la región poniente y norte de Nuevo León es considerada como la mayor zona de petrograbados en México y una de las más ricas de América (Lemus, 2014). En efecto, "Boca de Potrerillos", única zona arqueológica declarada en Nuevo León, registra más de 15000 imágenes talladas en piedra con una antigüedad de entre 6000 y 8000 años.

Las obras de infraestructura energética del noreste de México -en particular en Nuevo León entre 2013 y 2015-, han dado pie al descubrimiento de más de 200 sitios. Tan solo con la construcción del gasoducto Los Ramones, inaugurado en 2015, se descubrió una serie de vestigios arqueológicos. En efecto, esta es la zona norte y oriente que ha sido determinada por el Gobierno del estado de Nuevo León como la zona esencial para la extracción de gas shale, pues forma parte de la Cuenca de Burgos.

Aunque el procedimiento se hace a una profundidad de más de un kilómetro del subsuelo, el patrimonio arqueológico (a nivel de suelo) y el paleontológico (subterráneo) invariablemente serían afectados. Sin duda, las zonas de la entidad más afectadas serían la región norte y oriente, ya que estas cuentan con zonas arqueológicas descritas como "monumentales".

\section{LOS PROYECTOS DE INFRAESTRUCTURA Y DESARROLLO EN MATERIA ENERGÉTICA Y LOS DERECHOS HUMANOS}

Las reformas constitucionales de los últimos años en México, especialmente la de derechos humanos en 2011 y, más recientemente, la reforma en materia energética en 2013, han puesto en el centro del debate la actividad del Estado, principalmente la tarea de los jueces, al garantizar el respeto de los derechos de las personas y de los grupos de la sociedad que pudieran verse afectados por los grandes proyectos 
e inversiones que se generarán a partir de la entrada del sector privado nacional e internacional en la industria de los hidrocarburos y la electricidad.

Lo que resulta importante señalar es que México es uno de los 12 países, que junto con otros 11, alberga el $70 \%$ de la biodiversidad total del planeta (Boege, 2008). Conceptos como el "neoextractivismo" se han formulado para caracterizar este periodo histórico sin igual con otros procesos de explotación de la naturaleza (Composto, 2012). Se trata de un proceso masivo y creciente de explotación de bienes para su incorporación al mercado de la economía global. El rostro de este nuevo proceso no se centra como otrora en el petróleo y minería, sino en la explotación forestal o biocombustibles. En suma, se trata de una nueva forma de explotación basada en los recursos naturales y la expansión hacia territorios antes considerados como no productivos.

En este sentido, la protección a los derechos humanos cobra especial relevancia en relación con las personas y grupos vulnerables que puedan verse afectados por las obras de desarrollo e infraestructura que traerá la privatización de los energéticos en México. El reconocimiento de los derechos humanos pone a los operadores jurídicos ante la necesidad de contar con un marco jurídico aplicable y conocido por todos.

Por tanto, la fuerza vinculante de la jurisprudencia emitida por la Corte IDH se desprende del propio mandato constitucional establecido en el artículo 1 de la Constitución mexicana, ya que el principio pro-homine obliga a los jueces nacionales a resolver atendiendo a la interpretación más favorable a la persona. Veamos algunos casos que han sentado las bases sobre las cuales los derechos humanos deberán ser respetados y protegidos por el Estado mexicano en los casos de los proyectos de desarrollo e infraestructura en el caso de los energéticos y su relación con el derecho humano al agua.

Igualmente, desde el ámbito jurisdiccional se han generado esfuerzos para analizar el nuevo contexto global en el que se relacionan los gobiernos y las empresas y el papel que estas tienen en los proyectos de desarrollo e infraestructura dentro de este marco económico de nuestro siglo (SCJN, 2014).

Para efectos de este tema entenderemos como proyectos de desarrollo e infraestructura la definición adoptada por "Protocolo de actuación para quienes imparten justicia en los casos relacionados con proyectos de desarrollo e infraestructura" emitido por la Suprema Corte de Justicia de la Nación. Se trata de aquellos emprendimientos impulsados por empresas o Estado en zonas rurales o urbanas que tengan fines comerciales o que se lleven a cabo bajo el argumento del bien común, suponen la adquisición, disposición, arriendo u ocupación de espacios territoriales, generando un impacto sobre la vida de las personas o comunidades que las habitan, de las que ellos dependen y una posible afectación a sus derechos humanos (SCJN, 2014, 11).

Es decir, el análisis judicial de un proyecto de desarrollo desde la visión de los derechos humanos, como el Proyecto Monterrey VI, deberá recurrir al uso de la ponderación que permita determinar el escenario más favorable, teniendo en cuenta 
el catálogo de derechos humanos. Esta situación de conflicto es lo que los tribunales han enfrentado recientemente. Factores como el bien común o bienestar general deben contraponerse con derechos como consulta, identidad cultural, derecho a la vida o integridad personal y el derecho a la salud. En efecto, la mayor dificultad a la que los juzgadores se enfrentan es el distinguir entre aquellos derechos que no admiten restricción alguna y otros que pueden ser limitados en virtud de otros.

Otro de los rasgos de este tipo de proyectos es la cantidad de recursos económicos y financieros con los que se impulsan. Esta peligrosa combinación de inversión y tiempo limitado en un determinado territorio puede generar rápidas y profundas transformaciones en los sitios donde se instalan. Este impacto trae consigo, por ejemplo, desocupación de tierras o movilidad de poblaciones enteras para la instalación de estos proyectos, como el caso de una presa, hidroeléctrica, explotación de petróleo o gas, por mencionar algunos supuestos.

Estos cambios en la forma de vida se pueden convertir en violación a los derechos de las personas o comunidades ahí alojadas. Como el caso del derecho de propiedad privada, las afectaciones a la salud, la imposibilidad de acceso al agua y a la alimentación o el daño al medioambiente. Y ni qué decir de los sitios históricos o arqueológicos. Es decir, la falta de conocimiento y de transparencia de los procesos que se llevan a cabo regularmente son cuestiones técnicas de complejidad para el no experto. Estas acciones implican reforzar la exclusión y la discriminación en la toma de decisiones de dichos proyectos.

Un aspecto de mayor relevancia es señalar que en México existen 31785 núcleos agrarios de los cuales 29442 son ejidos y 2343 comunidades que ocupan más de 101 millones de hectáreas, lo que representa el $51 \%$ del territorio nacional, superficie en la que habitan más de 5 millones de personas. El procurador agrario en México, Cruz Aguilar, señaló que si bien la propiedad social es más del $50 \%$, también lo es que el aprovechamiento de los recursos energéticos en las modalidades de exploración y extracción se da en gran medida en la propiedad social (Saldaña, 2015).

En el caso de México, la reforma constitucional abrió al sector privado las inversiones en materia de hidrocarburos y electricidad y se espera que en los próximos años veamos estos proyectos en marcha. Sin embargo, el contexto constitucional en derechos humanos impone nuevas obligaciones a quienes emprendan proyectos en esta materia, tanto del sector privado como el público.

En efecto, este nuevo marco jurídico en materia energética impone acciones preventivas en materia social. Contempla también la necesidad de realizar estudios para identificar grupos sociales en situación de vulnerabilidad en las áreas donde se realizarán las actividades de la industria energética. Es decir, los propietarios de derechos reales, ejidales o comunales, cuando estos resulten afectados por algún proyecto de exploración, extracción, reconocimiento y exploración superficial de hidrocarburos o tendido de ductos para su transporte.

Por lo anterior, tomando en cuenta este espacio internacional y nacional, resulta, por un lado, la necesidad de revisar los conceptos normativos que regulan la actividad 
del sector energético, pero también, deriva pertinente analizar los referentes de la justicia interamericana que nos permitan conocer el contenido y alcance de los derechos humanos por estos proyectos en materia energética en nuestro país, haciendo especial énfasis en aquellas obligaciones referidas a la protección del derecho humano al agua.

\section{LA VISIÓN INTERAMERICANA DE LOS DERECHOS HUMANOS EN RIESGO}

\section{a. Derecho a la propiedad y a sus recursos naturales}

La propiedad de las poblaciones indígenas según el artículo 27 constitucional señala que "la ley protegerá la integridad de las tierras indígenas". A partir del control de convencionalidad del artículo $1^{\circ}$ de la Constitución, en este tema es de particular relevancia recurrir a los tratados internacionales que informan sobre el contenido del derecho. Así, tenemos el Convenio 169 de la Organización Internacional del Trabajo (OIT) que define el concepto de territorio como la totalidad del hábitat de las regiones que los pueblos interesados ocupan o utilizan de alguna manera. Podemos ver que esta definición va más allá del concepto de tierra como un bien de mercado, ya que hace referencia a la dimensión vital y simbólica que tiene ese espacio para la reproducción de las culturas.

En este sentido, la Corte Interamericana de Derechos Humanos ha desarrollado ampliamente los alcances de este derecho. En varias de sus resoluciones y con base en el derecho de propiedad establecido en el artículo 21 de la Convención Americana sobre Derechos Humanos (CADH), la Corte IDH enfatiza la importancia que la propiedad territorial tiene para los pueblos indígenas como base fundamental para el desarrollo de su cultura, su vida espiritual, su integridad y su supervivencia económica. Por ello, este derecho es reivindicado en sí mismo, pero también como condición para la realización de otra serie de derechos como los derechos a una vida digna, a la alimentación, al agua, a la salud, a la vida, al honor, a la dignidad, a la libertad de culto y de conciencia, a la libertad de asociación, a los derechos de la familia, la libertad de tránsito y el derecho a la residencia.

Tres casos exponen claramente este pronunciamiento. El caso Yakye Axa vs Paraguay (Serie C No 125, 2005); el caso de la comunidad indígena Sawhoyamaxa vs. Paraguay (Serie C No. 146, 2006) y el caso de la Comunidad Mayagna (Sumo) Awas Tingni vs. Nicaragua (Serie C No. 79, 2001). En ellos utilizó el Convenio 169 de la OIT para enfocar las disposiciones de la CADH relativas al derecho de propiedad privada previstas en el artículo 21 de dicha Convención. Bajo esta luz, la Corte IDH entiende que la cultura de los miembros de las comunidades indígenas corresponde a una forma de vida particular de ser, ver y actuar en el mundo, constituido a partir de esa estrecha relación con sus tierras tradicionales y recursos naturales, no solo por ser éstos su principal medio de subsistencia, sino además porque constituyen 
un elemento integrante de su cosmovisión, religiosidad y, por ende, de su identidad cultural (Serie C No. 146, 2006, párrafo 118; Serie C No. 79, 2001, párrafo 149).

En el caso de la comunidad indígena Yakye Axa, las tierras de la comunidad también fueron vendidas a empresas británicas. Estas empresas levantaron estancias ganaderas donde emplearon a algunos de los miembros de la comunidad. Pero dadas las condiciones de vida que tenían en estas estancias, se trasladaron a otra extensión de tierra y desde 1996 se asentaron en el costado de la carretera. Sin ningún servicio público disponible. En este caso, la Corte IDH fue clara al señalar que al desconocerse el derecho ancestral de los miembros de las comunidades indígenas en sus territorios se afectan otros derechos básicos como el derecho a la identidad cultural, y la supervivencia misma de las comunidades y sus miembros (Serie C No. 146, 2006, 147).

Además, consideró la violación al derecho a la vida, pues el Estado no otorgó las condiciones para una vida digna, en especial si se trata de personas en situación de vulnerabilidad y riesgo, como es el caso. Asimismo, la comunidad sufrió de afectaciones especiales del derecho a la salud, la alimentación, el acceso a agua limpia, todo ello impacta en el derecho a una existencia digna y las condiciones básicas para el ejercicio de otros derechos humanos, como el derecho a la educación o el derecho a la identidad cultural (Serie C No. 146, 2006, 167).

En el caso Sawhoyamaxa, la comunidad había perdido sus tierras porque fueron individualizadas y figuran a nombre de compañías privadas. Al iniciar el proceso de reivindicación de sus tierras no tuvieron éxito. Como consecuencia de las presiones recibidas por los propietarios de las fincas, los miembros de esta comunidad vivían en situación de pobreza extrema, bajos niveles de salud y atención médica, explotación laboral y restricciones para poseer cultivos y ganado propio. Por lo que la mayoría de los miembros decidieron salir de la comunidad y se asentaron al borde de la carretera nacional en condiciones de extrema miseria y sin ningún tipo de servicios.

La Corte IDH resolvió que los miembros de la comunidad Sawhoyamaxa tienen el derecho a solicitar que se les devuelvan sus tierras tradicionales aun cuando estas se encuentren en manos privadas y no tengan plena posesión de ellas.

Además, señala que cuando el Estado se vea imposibilitado a devolverlas, debe adoptar las medidas necesarias para restituir las tierras tradicionales y los recursos comunales a las poblaciones indígenas, por lo que deberá entregarles tierras alternativas de igual extensión y calidad, que serán escogidas de manera consensuada por los miembros de los pueblos indígenas, conforme a sus propias formas de consulta y decisión (Serie C No. 146, 2006, 135).

La utilización de tratados internacionales en la interpretación de la Convención Americana abre un rol importante para delimitar el contenido y alcances de los derechos humanos. Varios de estos instrumentos se relacionan con la vida y la salud humana, como por ejemplo, el Convenio de Estocolmo sobre Contaminantes Orgánicos Persistentes. En el caso Comunidad Mayagna (Sumo) Awas Tingni vs. 
Nicaragua en 2001, la Corte destacó la importancia de los estudios de impacto ambiental para prevenir riesgos y adoptar las medidas de seguridad necesarias, así como la importancia del consentimiento y participación de las comunidades en las decisiones sobre proyectos económicos. Un estudio no es suficiente en sí mismo para la protección de este derecho, se requiere indispensable la consulta a la comunidad con vistas a obtener su consentimiento. Consultas que deben ser libres e informadas, esto es, dar a conocer de manera oportuna y culturalmente apropiada los resultados de los estudios de impacto ambiental.

\section{b. Derecho a la consulta y el acceso a la información}

El derecho a la consulta es uno de los derechos humanos de las comunidades indígenas que más relevancia e importancia ha tomado en las decisiones de la Corte IDH de los últimos años. Precisamente, por su relación con los proyectos de desarrollo en materia de hidrocarburos, electricidad, forestales, entre otros. En México, este derecho a la consulta se encuentra previsto limitadamente en la fracción IX del apartado $\mathrm{B}$ del artículo $2^{\circ}$ de la Constitución. El precepto señala como obligación del Estado, a través de las entidades y municipios el consultar a los pueblos y comunidades indígenas en la elaboración de un Plan Nacional de Desarrollo (previsto en el artículo 26 constitucional) y, en su caso, incorporar las recomendaciones o propuestas que hagan.

Sin embargo, el derecho internacional proporciona un marco regulador más amplio a partir del el artículo 6.1 del Convenio 169 de la OIT en el que se reconoce el derecho a una consulta. De acuerdo con dicho Convenio, es obligación de los Estados:

a) consultar con los pueblos indígenas, mediante procedimientos apropiados y a través de las instituciones representativas, cada vez que se prevean medidas legislativas o administrativas susceptibles de afectarles directamente;

b) establecer los medios a través de los cuales los pueblos puedan participar libremente en la adopción de decisiones en instituciones y organismos administrativos y de otra índole responsable de políticas y programas que les conciernan;

c) establecer los medios para el pleno desarrollo de las instituciones e iniciativas de esos pueblos y en los casos apropiados proporcionar los recursos necesarios para tal fin.

En este sentido, la Corte IDH ha sentado diversos precedentes para definir los alcances del derecho a la consulta en casos específicos. Pero más recientemente, en el 2012, se pronunció directamente sobre el ejercicio de este derecho en el caso pueblo indígena Kichwa de Sarayaku vs. Ecuador (Serie C No. 245, 2012). En el 2004 se registró el estatuto del pueblo originario Kichwa de Sarayaku, pero en 1996 se había suscrito un contrato de exploración de hidrocarburos y explotación de petróleo en el bloque 23 de la región amazónica entre una empresa estatal y el consorcio formado por dos empresas privadas de capital extranjero. El espacio territorial que se 
otorgó para la concesión comprendía 200 mil hectáreas dentro de las que habitaban comunidades y pueblos indígenas, como el pueblo en cuestión.

La población se negó en repetidas ocasiones a la entrada a su territorio para la explotación petrolera. Sin embargo, en 2002 se inició la fase de exploración sísmica y entró una de las compañías al territorio ancestral. Esto ocasionó que la comunidad detuviera sus actividades económicas, administrativas y escolares y se organizaran para impedir la entrada. En respuesta a esto, la empresa abrió trochas sísmicas, siete helipuertos, destruyó cuevas, fuentes de agua y ríos subterráneos, taló árboles y plantas de valor medioambiental, que además eran el sustento alimentario de la tribu de Sarayaku. En 2010, la empresa estatal de petróleo firmó convenio de terminación con la empresa sobre el contrato para la exploración y explotación del petróleo crudo en esta zona. Pero el pueblo no fue informado de esto ni de los términos de la negociación del acta de terminación.

La Corte IDH facilitó lineamientos en relación con el derecho a la consulta. Señaló que el Estado debe consultar activamente y de manera informada con dicha comunidad y según sus costumbres y tradiciones, en el marco de una comunicación constante entre las partes. Además, las consultas deben realizarse de buena fe, a través de procedimientos culturalmente adecuados y tener como fin llegar a un acuerdo. Sobre todo, ha hecho énfasis que la consulta debe ser en las primeras etapas del proyecto de inversión o desarrollo. Y debe tomar en cuenta los métodos tradicionales del pueblo o comunidad para la toma de decisiones, ya que el no cumplimiento de esta obligación compromete la responsabilidad internacional del Estado en el respeto a sus derechos (Serie C No. 245, 2012, 177).

Con respecto a lo anterior, la jurisprudencia de la Corte IDH evidencia que el consentimiento sería exigible cuando los derechos de los pueblos indígenas que son esenciales para su supervivencia se pongan en riesgo. Ello pudiera comprender, no solo los proyectos de inversión o desarrollo sino también las actuaciones del Estado para el reasentamiento o traslados poblacionales y el almacenamiento o desecho de materiales peligrosos en territorios indígenas.

En caso de que no se lograra el acuerdo o consentimiento en el proceso de consulta, el Estado podría proceder con una medida propuesta solo si pudiera garantizar que no tuviese impactos significativos sobre los derechos de estos pueblos, tales como su derecho a establecer sus propias prioridades para el desarrollo como parte de su derecho a la libre determinación, el derecho a la salud y un medio ambiente sano, el derecho a la cultura y a la religión y los derechos de los pueblos indígenas sobre sus tierras y recursos naturales de acuerdo con sus usos y costumbres.

En el caso de que los proyectos de inversión o desarrollo afectaran el modo de vida o subsistencia de los pueblos indígenas o bien que impliquen el reasentamiento o traslados poblacionales y el almacenamiento o desecho de materiales peligrosos en territorios indígenas. O bien, si no hay acuerdo o consentimiento mediante el proceso de consulta, el Estado podría proceder con una medida propuesta solo si pudiera garantizar que no tuviese impactos significativos sobre los derechos de estos 
pueblos, tales como su derecho a establecer sus propias prioridades para el desarrollo como parte de su derecho a la libre determinación, el derecho a la salud y un medio ambiente sano, el derecho a la cultura y a la religión y los derechos de los pueblos indígenas sobre sus tierras y recursos naturales de acuerdo con sus usos y costumbres.

En ningún caso deberían ser vulnerados estos derechos. Aun en los casos en que el consentimiento no fuera estrictamente necesario, el Estado debe actuar de manera que respete y proteja los derechos humanos de los pueblos, lo que pudiera incluir la aplicación de otras salvaguardas, tales como el establecimiento de medidas de mitigación y compensación.

Como lo ha establecido en otras ocasiones, como en el caso Rosendo Cantú y otra vs. México, la Corte IDH aplicando el principio de no discriminación y con la finalidad de garantizar que estas comunidades tengan acceso a la justicia, es indispensable que los Estados otorguen esta protección efectiva tomando en cuenta sus particularidades propias, sus características económicas y sociales, así como su especial situación de vulnerabilidad. Esto incluye, entre otras cosas, el contar con atención médica, intérpretes y todas aquellas medidas que hagan posible su derecho consuetudinario, valores, usos y costumbres (Serie C No. 216, 2010).

\section{c. Derecho al agua y la afectación de otros derechos}

El derecho a la vida y a la integridad personal nuevamente fue pronunciado al resolver el caso Comunidad Indígena Sawhoyamaxa vs. Paraguay (Serie C No. 146, 2006). En este sentido, es significativa la sentencia porque el Tribunal creyó que a partir de 1997 el Estado tenía conocimiento del riesgo real y de la situación de vulnerabilidad en la que permanecían los miembros de esta comunidad; especialmente, los niños, mujeres embarazadas y ancianos, así como el hecho de su mortandad (Serie C No. 146, 2006, 159).

El despojo de la propiedad de la tierra trajo consigo el desempleo, analfabetismo, tasas de morbilidad por enfermedades evitables, desnutrición y las limitaciones de acceso y uso de los servicios públicos de salud y agua potable, así como la marginación por causas económicas, geográficas y culturales. Todo ello constituyó impedimento para acudir a los centros asistenciales de salud. En este sentido resulta gráfico el argumento empleado en la sentencia al considerar que los enfermos que pudieron llegar a un centro asistencial lo hicieron de manera tardía o fueron tratados de forma denigrante para la condición humana. De ahí que razonó que las muertes de los miembros de la comunidad fueron atribuibles al Estado. Especial tratamiento hace la sentencia en cuestión sobre el derecho a la vida de los niños y mujeres embarazadas al no contar con el acceso adecuado a servicios de atención médica (Serie C No. 146, 2006, 168, 174, 177, 178).

Por otra parte, en la sentencia dictada en razón del caso Comunidad indígena Yakye Axa vs Paraguay (Serie C No. 125, 2005), la Corte IDH tuvo oportunidad de reiterar los alcances del derecho a la vida y la obligación del Estado en su posición de garante. En este caso, la Corte estableció que el Estado generó las condiciones que agudizaron 
las dificultades de acceso a una vida digna a los miembros de la comunidad al vivir en condiciones de pobreza extrema y precariedad en sus asentamientos.

En este sentido, enfatizó que el Estado generó condiciones que llevaron a la vulneración del derecho a la vida digna y al deber de desarrollo progresivo, lo cual llevó a afectar otros derechos como el derecho a la salud, el derecho a un medioambiente sano, el derecho a la alimentación y al agua limpia, así como el derecho a los beneficios de la cultura (Serie C No. 125, 2005, 163 y167). Es de la mayor relevancia destacar que esta sentencia hace pronunciamiento en defensa de los derechos de los niños y de las personas de edad avanzada de la comunidad (Serie C No. 125, 2005, 172 y 175).

Por otra parte, el derecho al agua y a la alimentación fue motivo de análisis en relación con el derecho a la vida y la salud, en ocasión del caso Comunidad Indígena Xákmok Kásek vs. Paraguay (Serie C No. 214, 2010). Aquí sustentó que las afectaciones al derecho a la vida digna se ven reflejadas en la falta de agua en cantidad y calidad suficiente que no los exponga a enfermedades (Serie C No. $214,2010,195)$. Contar con alimentación en cantidad y calidad suficientes para las necesidades básicas diarias y el acceso a servicios de salud y a servicios educativos para los niños y niñas de la comunidad (Serie C No. 214, 2010, 200, 208, 213).

Como puede observarse esta sentencia es del mayor interés porque además de reiterar el derecho a la vida concibe y presenta la afectación al derecho a la integridad cultural que sufrió esta comunidad. La afectación a este derecho se deriva de analizar las condiciones de vida de los miembros de la comunidad. Así, llega a la conclusión que debido a la falta de restitución de sus tierras tradicionales, la pérdida paulatina de su cultura y la larga espera que han debido soportar en el transcurso del ineficiente procedimiento administrativo; adicionalmente, las condiciones de vida miserables, la muerte de varios de sus miembros y el estado general de abandono en el que se encuentran generan sufrimientos que afectan la integridad psíquica y moral de todos los miembros de la comunicad, todo ello constituye una violación del artículo 5 de la CADH en perjuicio de los miembros de la comunidad (Serie C No. 214, 2010, 244).

El derecho a la vivienda es uno de los derechos que también debe considerarse dentro de los derechos para proteger con motivo de los proyectos de desarrollo e infraestructura. Veamos algunos ejemplos que ilustren esta relación. La Corte IDH ha desarrollado un concepto amplio sobre el derecho a la propiedad en el que incluye el derecho a una vivienda adecuada que tiene conceptos como bienes materialmente definidos como las cosas inmateriales (Serie C No. 198, 2009).

El mismo criterio sostuvo en el caso Salvador Chiriboga vs. Ecuador (Serie C No. 179, 2011) cuando señaló que la propiedad abarca, entre otros, el uso y goce de los bienes, definidos como cosas materiales apropiables, así como todo derecho que pueda formar parte del patrimonio de una persona. Dicho concepto comprende todos los muebles e inmuebles, los elementos corporales e incorporales y cualquier otro objeto inmaterial susceptible de valor (Serie C No. 179, 2011, 55). 
En relación con el derecho a la alimentación la Corte IDH también ha establecido criterios sobre el cumplimiento de este derecho por parte del Estado. Así, en el caso que hemos comentado sobre la Comunidad Indígena Yakye Axa vs. Paraguay y Xákmok Kásek vs. Paraguay, en ambos casos las afectaciones que sufrieron los miembros de estas comunidades, al ser privados de sus territorios ancestrales y obligados a vivir a un costado de la carretera, tuvo afectaciones especiales en el derecho a la alimentación y el acceso al agua limpia, las cuales impactan en el derecho a una vida digna (Serie C No. 146, 2006, 167).

En particular, en el caso Xákmok Kásek vs. Paraguay la Corte IDH hizo un interesante análisis sobre la cantidad de alimentos que el Estado proporcionó a esta comunidad indígena durante varios periodos (mayo de 2009 a marzo de 2010). Llegó a la conclusión que lo otorgado por el Estado en este periodo correspondería a 0.29 $\mathrm{kg}$ de alimentos por persona por día. En consecuencia, estimó que esta cantidad de alimento es insuficiente para satisfacer medianamente las necesidades básicas diarias de alimentación de cualquier persona (Serie C No. 214, 2010, 200).

En este asunto, la Corte realizó el mismo análisis sobre los litros de agua por día que recibía cada persona de la comunidad. De acuerdo con el estándar internacional de la Organización Mundial de la Salud señaló que una persona requiere de mínimo 7.5 litros por día para satisfacer el conjunto e necesidades básicas, es decir, incluye alimentación e higiene. Aplicando esta medición arribó a la conclusión que las gestiones del Estado para proveer a los miembros de la comunidad agua suficiente y calidad adecuada, no fue suficiente y no demostró que los miembros de la comunidad tengan acceso a fuentes seguras de agua, por lo cual, los expuso a riesgos y enfermedades (Serie C No. 214, 2010, 195, 196).

\section{EL DERECHO AL AGUA EN MÉXICO: CASO DE LA TRIBU YAQUI}

En el 2010 el gobierno mexicano impulsó la construcción y operación del proyecto "Acueducto Independencia". Por sus dimensiones se trata de un proyecto de desarrollo e infraestructura, similar por su objetivo al Proyecto Monterrey VI. La autorización es para la realización del acueducto en varios municipios del estado de Sonora, que consisten en la construcción y operación de: a) una obra de toma vertical en la presa El Novillo; b) una estación de rebombeo horizontal (cárcamo de bombeo); c) un acueducto de acero para la distribución de agua nacional y, d) una línea de transmisión eléctrica, sin que se desprenda pronunciamiento respecto a la restricción de los derechos de disposición.

En este asunto, la tribu Yaqui consideró lesionados sus derechos ya que desde 1940 por decreto del entonces presidente Lázaro Cárdenas esta comunidad tiene el derecho de disponer del 50\% del agua del río para su subsistencia. Alegan el daño medioambiental causado en el territorio yaqui, pero sobre todo, se alega que se vieron despojados del derecho al agua, que les pertenecía y que el proyecto se llevó a cabo sin realizar ningún tipo de información ni consulta hacia la comunidad indígena. 
Ante este problema, los representantes tradicionales de la tribu Yaqui del pueblo de Vícam, Sonora, interpusieron un amparo por las violaciones a sus derechos humanos al territorio, a la consulta y a un medio ambiente sano.

En mayo de 2012 el juez Cuarto de Distrito concedió el amparo a la tribu Yaqui. Luego de resolver el amparo en revisión interpuesto por la Secretaría del Medioambiente, el 8 de mayo de 2013, la Suprema Corte de Justicia de la Nación ordenó al Estado mexicano realizar la consulta para identificar si la construcción del acueducto ocasiona algún daño irreparable y de ser así, la construcción-operación del acueducto debería ser suspendido, independientemente de la etapa en que se encuentre (Amparo en Revisión 631/2012).

Interesa aquí resaltar que la Corte Suprema mexicana usó jurisprudencia emitida por la Corte IDH que hemos analizado -como el caso Sarayaku- y el Convenio 169 de la OIT para determinar que la consulta debió ser previa, culturalmente adecuada, informada, y de buena fe, con la finalidad de llegar a un acuerdo.

Esto es, el deber por parte del Estado a la consulta para los pueblos y comunidades indígenas no depende de la demostración de una afectación real a sus derechos, sino de la susceptibilidad de que puedan llegar a dañarse, pues precisamente uno de los objetos del procedimiento es determinar si los intereses de los pueblos indígenas serían perjudicados.

La Corte mexicana reiteró en agosto de 2013 -debido a la solicitud de las autoridades responsables-, que se deja sin efectos la autorización para la construcción del proyecto hídrico de referencia hasta que las autoridades competentes realicen la consulta conforme al estándar establecido por la Corte Interamericana y las exigencias realizadas por el tribunal mexicano. Esto con el fin de determinar si el proyecto genera algún daño irreparable a la tribu y, en caso de haber alguna afectación el proyecto podrá suspenderse, independientemente de la etapa en que se encuentre (Aclaración de Sentencia, 2013).

Sin duda, la resolución de la Primera Sala de la Suprema Corte de Justicia es un referente importante en materia de derecho al territorio, al agua y a la consulta de pueblos y comunidades indígenas, pues reconoce, por primera vez en México, los estándares interamericanos en materia de derecho a la consulta de los pueblos indígenas. Cabe señalar, sin embargo, que la sentencia del Amparo en Revisión no precisó los efectos o alcances del amparo otorgado. Como lo ha señalado Cossío (2014) esto podría repercutir en un futuro debilitando los incentivos para que las autoridades realicen las consultas de manera previa, de forma culturalmente adecuada, informada y de buena fe, tal como lo indica la propia sentencia de amparo.

En este caso, se ha precisado (Cossío, 2014, p. 4) que la sentencia debió establecer el que dejara de operar el acueducto hasta en tanto se emitiera una nueva resolución en materia de impacto ambiental en los términos de la sentencia; es decir, hasta que se realizara la consulta a la comunidad indígena, siguiendo los lineamientos que la sentencia estableció, como se dictaminó en la Aclaración de la sentencia del juicio original. 
En otro criterio judicial diverso, también en 2014 se definió que el vital líquido es un recurso natural limitado y un bien público fundamental para la vida y la salud, como derecho humano resulta indispensable para la realización de otros derechos humanos, por lo que el agua, las instalaciones y lo servicios deben ser accesibles para todos. Además, agrega la tesis que el Estado debe velar por que la asignación de los recursos de agua y las inversiones faciliten su acceso a todos los miembros de la sociedad, pues las transformaciones no deben ser a beneficio de una fracción privilegiada de la población, sino invertirse en instalaciones y servicios que redunden a favor de un sector más amplio (Amparo en Revisión, 2014).

Más recientemente, en abril de 2015, el Segundo Tribunal Colegiado en Materia Administrativa del Séptimo Circuito, con sede en Boca del Río, Veracruz, concedió una suspensión que protege el entorno ecológico y el derecho humano al agua de comunidades indígenas, y suspende la construcción de mini-centrales eléctricas. Esto en virtud de la resolución de un juez que negó la suspensión de la obra al considerar que no se advertía la afectación o menoscabo ecológico en la población donde habitaban.

Sin embargo, el Tribunal Colegiado al conocer el recurso aplicó el principio In dubio pro natura, que establece que de existir peligro o amenaza de daños graves o inminentes sobre elementos de biodiversidad, la ausencia de certeza científica no es obstáculo para dictar medidas que conserven el medio ambiente.

Esta decisión evitará que se afecte el entorno ecológico de las comunidades indígenas, en específico el derecho humano al agua, evitándose un daño irreversible en los manantiales situados en dichos sectores desprotegidos de la vida nacional.

\section{COMENTARIO FINAL}

Una evaluación de las condiciones internas de cada región en México es crucial para entender el tipo de conexiones que ella puede establecer con la economía internacional. El AMM mostró tener desde fines del siglo XIX una comunidad de empresarios y negocios con suficiente poder económico, influencia política y experiencia para participar y beneficiar económicamente a la región en su conjunto, en particular, durante el período de 1940 en adelante. La capacidad de esta elite empresarial rebasó el ámbito nacional y estableció alianzas estratégicas con firmas extranjeras para lanzar su proyecto económico a un nivel de clase mundial.

En su primera fase de desarrollo económico, esta elite supo crear las condiciones para la acumulación de capital gracias al intercambio de mercancías en la zona fronteriza. Posteriormente, a fines del siglo XIX y principios del XX, esculpió las bases de un desarrollo económico basado en la industria pesada. El ciclo industrial clásico se extendió por un centenar de años, pasando rápidamente a una economía de servicios. En este largo período de dominio, la industria pesada requirió importantes dotaciones de energía tales como el petróleo y el gas, inexistentes en el subsuelo neolonés. Las grandes obras de infraestructura (oleoductos y gasoductos) fueron 
financiados en parte por los empresarios locales y en buena medida por el Estado mexicano. Así es como llegó el petróleo y el gas a Monterrey través de zonas productoras tan lejanas como Cactus, Chiapas en México y de los campos del estado de Texas, en territorio estadounidense.

El siglo XXI muestra que esta experiencia no es exclusiva de este período, sino es parte de la evolución de las actividades económicas y sus gestores, en este caso el poderoso grupo empresarial local. El proyecto "Monterrey VI" muestra una vieja película en el nuevo carrete de presentación: la búsqueda del apoyo del Estado mexicano en la aprobación y construcción de un acueducto que traería millones de metros cúbicos de agua dulce extraídos del caudaloso río Pánuco a Monterrey. El objetivo no está del todo claro: agua para solventar en un futuro sequías de la urbe de cerca de cinco millones de habitantes y agua dulce para explorar la novedad minera global: la extracción de gas shale.

Sin embargo, no olvidemos que, a pesar de los diferentes supuestos sobre los que yacen los derechos humanos, todos ellos se encuentran ligados por un vínculo común que es la persona humana y su relación con el entorno. Así mismo, el más alto sentido de salud integral para una vida digna constituye no solo un derecho fundamental sino también el necesario contexto sobre el cual se puedan realizar todos los demás derechos de la persona.

Sin duda, el tema de los derechos humanos viene a impactar de manera muy importante con la reforma energética. En efecto, los proyectos de desarrollo e infraestructura que la apertura energética y eléctrica traerá consigo nos llevan a considerar los parámetros sobre los cuales se determinará la viabilidad de estos proyectos.

Ante tal panorama, la justicia tiene mucho que decir. Para ello la referencia a los criterios expuestos en la jurisprudencia de la Corte IDH es de suma importancia debido a que son de observancia obligatoria para todos los tribunales mexicanos. Sin duda, hay certeza en la necesidad de que las personas y comunidades afectadas por estos proyectos de inversión a gran escala vean protegidos su derecho a los recursos naturales, como el agua, el medioambiente, así como el derecho a la consulta y propiedad. También hay certeza al suponer un espacio de tensiones y resistencia, de vulnerabilidad y afectaciones a la vida entre el poder económico de la industria energética y la defensa de los derechos humanos por el otro. Por ello, el análisis de estos casos y la ayuda de expertos pueden dar la pauta para el establecimiento de las posibles contingencias en la ejecución de un determinado proyecto, creando potenciales pérdidas económicas y sociales para ambas partes.

La realidad que imponen los derechos humanos se vuelve vital para cualquier proyecto en materia de hidrocarburos, electricidad o de desarrollo económico en México. Este nuevo enfoque, sustentado en casos reales y en consecuencia leyes que han puesto los derechos humanos por encima del desarrollo económico, plantea retos para el respeto a los mismos derechos que tenemos como sociedad y, en consecuencia, ser congruente con la prosperidad económica de la capital industrial de México, la ciudad de Monterrey. 


\section{REFERENCIAS}

Boege, E. (2008). El patrimonio biocultural de los pueblos indigenas de México. México: Instituto Nacional de Antropología e Historia, Comisión Nacional para el Desarrollo de los Pueblos Indígenas.

Composto, C. (2012). Acumulación por despojo y neoextractivismo en América Latina; una reflexión crítica acerca del Estado y los movimientos socioambientales en el nuevo siglo. Astrolabio. Nueva Época, 8.

Cossío J. (2014). Voto concurrente en la sentencia al Amparo Directo 631/2012. Recuperada de http://www2.scjn.gob.mx/ConsultaTematica/PaginasPub/ DetallePub.aspx?AsuntoID=144699

De la Garza, R., \& De la Fuente, A. (2015). Conferencia Geología del subsuelo: El historial de los temblores y el fracking. Saltillo, Coahuila: Casa San José, 22 de marzo.

De la Garza, R. (2014). Red del Agua. Universidad Nacional Autónoma de México. Flores, O. (2009). Monterrey, una ciudad internacional, 1910-1980 (t. V, vol. I). México: Municipio de Monterrey.

Flores, O. (2010). Monterrey industrial, 1890-2000. México: Universidad de Monterrey.

Flores, L. (2015, 15 de mayo). Hacienda pone lupa a postulantes en Ronda Uno. Milenio, Sección Negocios, p. 26.

Instituto Nacional de Antropología e Historia. (2011). Atlas Interactivo. México: INAH, presentado el 21 de octubre de 2011. Recuperado de http:/quo.mx/ noticias/2011/10/21/atlas-interactivo-del-inah-con-google

Jiménez, G. (2014, 12 de marzo). Gas Shale. Gas, industria y agua, una excelente combinación: El proyecto Monterrey VI. Milenio. Recuperado de http://www. milenio.com/region/Monterrey_VI-extraccion_gas_shale-Cuenca_de_Burgossismos_en_NL_0_260974192.htm,

Lemus, G. (2014, 14 de diciembre). Desarrollo energético traería riesgo a zonas arqueológicas. Milenio. Recuperado de http://www.milenio.com/cultura/ Desarrollo-energetico-traeria-riesgo-arqueologicas-NL-alterar-desaparecerINAH_0_427157324.html

Ochoa, R. (2014, 17 de marzo). Advierten las consecuencias sobre el uso del método de "fracking". Milenio. Recuperado de http://www.milenio.com/negocios/ Advierten-consecuencias-uso-metodo-fracking_0_263973661.html

Rangel, J. (2015, 15 de mayo). Los candados del contrato petrolero. Milenio, Sección Negocios, p. 28.

Secretaría de Desarrollo Económico. (2014). Reto desarrollo regional energía 2014. Monterrey: Gobierno del Estado de Nuevo León.

S/A. (2015, 12 de mayo). México licitará 26 campos en la fase tres de la Ronda Uno. CNNExpansión, Recuperado de http://www.cnnexpansion.com/ 
economia/2015/05/12/mexico-licitara-26-campos-en-la-fase-tres-de-la-rondauno

S/A. (2015, 11 de marzo). Ley de Aguas, una ley discriminatoria. Ciudadanía express. com. Recuperado de http://ciudadania-express.com/index.php/2015/03/11/leyde-aguas-una-ley-discriminatoria/

Saldaña, E. (2015, 09 de abril). Nuevo marco jurídico en materia energética establece acciones preventivas en materia social. Canal judicial. México: Suprema Corte de Justicia de la Nación. Recuperado de https://mail.google.com/mail/ $\mathrm{u} / 0 / \#$ search/canal+judicial/14ca08a5a2d52a54

Suprema Corte de Justicia de la Nación. (2013). Protocolo de actuación para quienes imparten justicia en casos que involucren derechos de personas, comunidades y pueblos indígenas. México. Recuperado de https://www.scjn.gob.mx/libreria/ paginas/protocolos.aspx

Suprema Corte de Justicia de la Nación. (2014). Protocolo de actuación para quienes imparten justicia en casos relacionados con proyectos de desarrollo e infraestructura. México. Recuperado de https://www.scjn.gob.mx/libreria/ paginas/protocolos.aspx

\section{Tesis y sentencias judiciales}

Sentencia (2001) de 21 de agosto. Caso comunidad Mayagna (Sumo) Awas Tingni vs. Nicaragua, Serie C No. 66 y Serie C No. 79. Corte Interamericana de Derechos Humanos. Recuperado de http://www.corteidh.or.cr/docs/casos/articulos/ Seriec_79_esp.pdf

Sentencia (2005) de 17 de junio. Caso comunidad indígena Yakye Axa vs. Paraguay, Serie C No. 125. Corte Interamericana de Derechos Humanos. Recuperado de http://www.corteidh.or.cr/docs/casos/articulos/seriec_125_esp.pdf

Sentencia (2006) 29 de marzo. Caso Comunidad Indígena Sawhoyamaxa vs. Paraguay, Serie C No. 146. Corte Interamericana de Derechos Humanos. Recuperado de http://www.corteidh.or.cr/docs/casos/articulos/seriec_146_esp2.pdf

Sentencia (2007) de 28 de noviembre. Caso del Pueblo Saramaka vs. Surinam, Serie C No. 172. Corte Interamericana de Derechos Humanos. Recuperado de http:// www.corteidh.or.cr/docs/casos/articulos/seriec_172_esp.pdf

Sentencia (2010) de 31 de agosto. Caso Rosendo Cantú y otra vs. México. Serie C No. 216. Corte Interamericana de Derechos Humanos. Recuperado de http://www. corteidh.or.cr/docs/casos/articulos/seriec_216_esp.pdf

Sentencia (2010) de 24 de agosto. Caso Comunidad indígena Xákmok Kásek vs. Paraguay, Serie C No. 214. Corte Interamericana de Derechos Humanos. Recuperado de http://www.corteidh.or.cr/docs/casos/articulos/seriec_214_esp. pdf 
Sentencia (2012) de 27 de junio. Caso del Pueblo indígena Kichwa de Sarayaku vs. Ecuador, Serie C No. 245. Corte Interamericana de Derechos Humanos. Recuperado de http://corteidh.or.cr/docs/casos/articulos/seriec_245_esp.pdf

Sentencia (2013). Amparo en Revisión 631/2012. 08 de mayo de 2013. Primera Sala de la Suprema Corte de Justicia de la Nación. Recuperado de http://www2.scjn. gob.mx/ConsultaTematica/PaginasPub/ResultadosPub.aspx?Tema $=\&$ Consecut ivo $=631 \&$ Anio $=2012 \&$ TipoAsunto $=2 \&$ Pertenecia $=1 \&$ MinistroID $=0 \&$ Secretar ioID $=0 \&$ MateriaID $=0$

Aclaración de Sentencia (2013). Amparo en Revisión 631/2012. 07 de agosto de 2013. Primera Sala de la Suprema Corte de Justicia de la Nación.

Contradicción de Tesis. (2013). 293/2011. 3 de septiembre de 2013. Gaceta del Semanario Judicial de la Federación, décima época, libro 5, t. I, tesis aislada P./J.21/2014 (10 $)$, p. 204. Registro 2006225.

Amparo en revisión. (2014). 158/2014. 2 de octubre de 2014. Gaceta del Semanario Judicial de la Federación, decima época, libro 12, t. IV, tesis aislada I.9 ${ }^{\circ}$.P.69P $\left(10^{\mathrm{a}}\right)$, p. 2928, Registro: 2008053.

\section{Legislación}

Constitución Política de los Estados Unidos Mexicanos.

Convenio sobre pueblos indígenas y tribales (1989). Número 169. Organización Internacional del Trabajo.

Convención Americana de Derechos Humanos. 